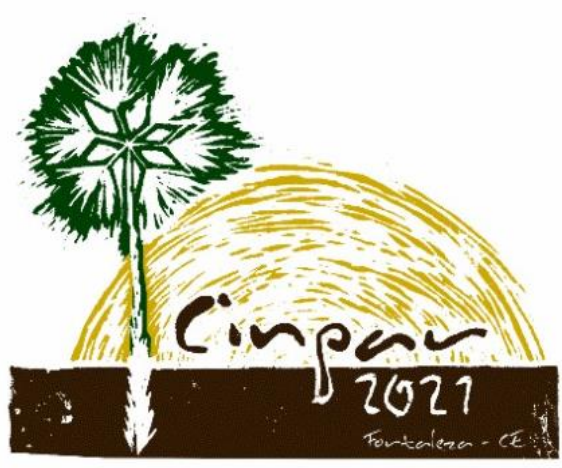

XVII Congresso Internacional sobre Patologia e Reabilitação das Construções

XVII Congreso Internacional sobre Patología y Rehabilitación de las Construcciones

XVII International Conference on Pathology and Constructions Rehabilitation

FORTALEZA (Brasil), 3 a 5 de junho de 2021 https://doi.org/10.4322/CINPAR.2021.043

\title{
Uso da termografia infravermelha como técnica para detecção de infiltrações em fachadas de edifícios - Estudo de caso em Salvador-BA
}

\section{Use of infrared thermography as technique for detecting infiltrations in building facades - Case study in Salvador-BA}

\author{
Francisco Gabriel Santos SILVA ${ }^{1}$, Vinícius Almeida COELHO ${ }^{2}$, Luanne Bastos de Britto BARBOSA ${ }^{3}$ \\ ${ }^{1}$ Universidade Federal da Bahia, Escola Politécnica - Departamento de Construção e Estruturas, Brasil, \\ fgabriel.ufba@gmail.com \\ ${ }^{2}$ Universidade Federal da Bahia, Escola Politécnica - Programa de Pós-graduação em Engenharia Civil, Brasil, \\ mrvoelho@gmail.com \\ ${ }^{3}$ Universidade Federal da Bahia, Escola Politécnica - Programa de Pós-graduação em Engenharia Civil, Brasil, \\ lubastosb@gmail.com
}

\begin{abstract}
Resumo: $O$ ingresso indesejado de umidade caracteriza-se como uma das principais patologias que acometem as edificações. Falhas nos componentes do sistema de impermeabilização causam diversos tipos de danos aos sistemas construtivos, como manchamentos, fissuração e desplacamentos, podendo ainda favorecer a degradação de outros elementos como as estruturas em concreto armado e levar ao comprometimento da habitabilidade e salubridade dos ambientes. O presente trabalho tem como objetivo avaliar manifestações patológicas de fachada decorrentes de infiltração em um edifício na cidade de Salvador - BA, fazendo uso da termografia infravermelha como principal técnica para detecção de regiões com concentração de umidade. Após identificação das áreas afetadas no interior da edificação, foram realizadas inspeções in loco com registros fotográficos das patologias na fachada com o uso de Drone/VANT, onde foram detectadas fissuras, empolamento de pintura e falhas no selante das juntas de movimentação. Finalmente, concluiu-se que as anomalias identificadas foram causadas principalmente pela movimentação higrotérmica do revestimento e danos no selante, sendo apresentadas as falhas que possivelmente levaram ao surgimento da patologia e propostas metodologias de tratamento para correção do problema.
\end{abstract}

Palavras-chave: Infiltração; Termografia; Patologia; Fachadas.

Abstract: The unwanted ingress of moisture is characterized as one of the main pathologies that affect buildings. Failures in the components of the waterproofing system cause various types of damage to construction systems, such as staining, cracking, detachment and may also favor the degradation of other elements such as reinforced concrete structures and lead to compromised habitability and healthiness of the environments. The present work aims to evaluate pathological manifestations of facades resulting from infiltration in a building in the city of Salvador - BA, using infrared thermography as the main technique for detecting regions with moisture concentration. After identifying the affected areas inside the building, on-site inspections were carried out with photographic records of pathologies on the facade using Drone/UAV, where cracks, paint blistering and flaws in the movement joints were detected. Finally, it was concluded that the anomalies identified were caused mainly by the hygrothermal movement of the coating and damage to the sealant, being presented the failures that possibly led to the appearance of the pathologies and proposed treatment methodologies to correct the problems.

Keywords: Infiltration; Thermography; Pathology; Facade. 


\section{Introdução}

A construção civil é um setor fundamental para o desenvolvimento e crescimento da sociedade, sendo o crescimento acelerado, uso de novos produtos e materiais inovadores com desenvolvimento de novas técnicas construtivas características inerentes ao setor. Contudo, tem-se observado a incidência cada vez maior de manifestações patológicas com origens diversas nos sistemas construtivos, devido tanto a falhas de projeto quanto de execução e uso de materiais inadequados (ANTUNES, 2010).

O surgimento de manifestações patológicas está associado diretamente ao desgaste das edificações. As patologias promovem redução do desempenho dos sistemas construtivos progressivamente até que sejam atingidos níveis críticos, podendo ocasionar danos superiores àqueles previstos nos planos de manutenção e exigir recursos consideráveis para o reparo e reabilitação das estruturas (DAL MOLIN et al., 2016).

A NBR 15575 (ABNT, 2013) define a vida útil das edificações como o período em que seus elementos e sistemas construtivos apresentam desempenho adequado frente às exigências para as quais foram projetados e construídos, considerando a manutenção periódica. Já a durabilidade pode ser entendida como a capacidade que uma estrutura possui em resistir satisfatoriamente à ação dos agentes degradantes, estando intrinsicamente ligada à sua vida útil, dependendo tanto das variáveis decorrentes da exposição ambiental quanto das condições de uso (SCHULER, 1998).

A fachada de uma edificação deve garantir acabamento estético, conforto e segurança aos usuários (RIBEIRO; BARROS, 2010), sendo considerado como o sistema construtivo mais exposto às condições adversas e agentes agressivos, portanto, o mais susceptível à ocorrência de fenômenos deletérios que prejudiquem seu desempenho (SOUZA, 2016). Estes fenômenos afetam as funções básicas das fachadas, comprometendo funções básicas como a valorização estética, econômica e a estanqueidade do edifício (ANTUNES, 2010).

A infiltração é uma das principais patologias encontradas nas edificações, caracterizada pela percolação indesejada de água. Sua origem é diversa, seja pela falta de sistemas de impermeabilização adequados ou mesmo ausência de manutenção de tais componentes, produzindo uma série de problemas e patologias que trazem diversos transtornos e prejuízos econômicos.

Dentre os principais tipos de infiltração que acometem as edificações, pode-se citar a presença de umidade por capilaridade, quando a água ascende do solo pelos poros capilares dos materiais; umidade de construção, resultante da secagem incompleta dos materiais desde a fase de obra; umidade de precipitação, advinda das chuvas, usualmente manifestada após períodos chuvosos prolongados e outras causas com natureza pontual, associadas a defeitos construtivos e ocorrência de danos por acidentes (CECHINEL et al., 2009).

Os danos associados a infiltração, como manchamentos, fissurações, gotejamento, formação de eflorescências, lixiviação, crescimento de microrganismos e corrosão, podem ser decorrentes da própria presença de umidade nos materiais ou do processo evaporativo, afetando diversos elementos das edificações, como pisos, paredes, tetos e estrutura. Tais fenômenos reduzem o desempenho dos sistemas construtivos e podem comprometer as condições de salubridade e habitabilidade das edificações (BARREIRA; ALMEIDA; DELGADO, 2016)

O uso de veículos aéreos não tripulados (VANT), ou Drones, é uma técnica que tem sido cada vez mais utilizada na construção civil, seja para situações de controle e acompanhamento de obra ou inspeções prediais e avaliações (LISBOA et al., 2018). Os drones facilitam a obtenção de informações de regiões de difícil acesso, onde normalmente seria necessário gasto com locação de equipamentos e ferramentas para realização de inspeções. Neste sentido, tem-se confirmado cada vez mais a eficiência dos drones como ferramenta para identificação de manifestações patológicas e registro de imagens de alta definição que favorecem a tomada de decisão sobre a necessidade de intervenções e ainda permitem que sejam feitos mapeamentos dos danos para acompanhamento das degradações (TONDELO; BARTH, 2019).

As técnicas tradicionais para deteç̧ão de infiltrações em edificações eram destrutivas, constituindo-se na quebra de material para verificação da presença de umidade, produzindo uma série de resíduos e transtornos. A termografia infravermelha atua como uma alternativa não destrutiva capaz de detectar 
pontos úmidos nas edificações de maneira rápida e eficaz, possibilitando ainda a detecção de danos não visíveis a olho nu (SANTOS; ROCHA; PÓVOAS, 2019).

A análise termográfica consiste na análise da temperatura superficial dos elementos estudados, podendo ser realizada tanto de forma quantitativa quanto qualitativa, sendo esta a mais usual. $\mathrm{Na}$ análise qualitativa, compara-se as variações de temperaturas nos termogramas em busca de anomalias no perfil térmico dos elementos expostos, sendo verificada expressiva variação de temperatura entre as regiões secas e úmidas devido à diferença entre o comportamento térmico de seus constituíntes e da água absorvida (ANDRADE; RESENDE, 2019).

Barreira, Almeida e Delgado (2016) explicam que a variação do comportamento térmico entre materiais com variados teores de umidade entre os materiais deve-se à redução de temperatura na superfície quando ocorre a evaporação da água e à maior capacidade térmica dos materiais no estado úmido, de modo que as regiões molhadas em um mesmo componente tendem a mudar sua temperatura mais lentamente do que o entorno, formando um padrão térmico heterogêneo. Tal fenômeno torna a técnica da termografia infravermelha adequada para deteç̧ão de umidade mesmo nos estágios iniciais das infiltrações, antes mesmo da ocorrência de manifestações superficiais (SANTOS; ROCHA; PÓVOAS 2019).

Dado o exposto, o presente trabalho objetivou analisar manifestações patológicas decorrentes de infiltração nas fachadas de uma edificação residencial fazendo uso da termografia infravermelha como principal técnica para detectar as regiões afetadas nos ambientes internos, procedendo com o diagnóstico do problema e apresentação de possíveis soluções.

\section{Metodologia}

\subsection{Objeto de estudo}

Foi analisada uma edificação residencial com 13 pavimentos, construída há aproximadamente 3 anos em estrutura convencional de concreto armado com alvenaria de vedação, fachadas com acabamento em pastilhas cerâmicas e textura, situada próxima ao mar em área com classe de agressividade ambiental tipo III - elevada conforme a NBR 6118 (ABNT, 2014).

\subsection{Metodologia}

Foi inicialmente realizada inspeção visual com captação de imagem por Drone/VANT (DJI Mavic Pro) e câmera de alto zoom profissional (Sony DSC H400) em toda a fachada sudeste da edificação (Figura 1), afetada por manchamentos, buscando-se sinais de danos, anomalias e vícios construtivos.

Como a vistoria foi realizada em período sem ocorrência de chuvas, foi feito teste de estanqueidade na fachada por meio da aplicação de água com uma mangueira, manuseada por funcionário descendo em cadeirinha. Após aplicação da água, foram escolhidas, por amostragem, unidades no 70 e 11으 pavimento para avaliação, sendo realizadas análises por termografia infravermelha, com câmera termográfica (FLIR C2 Profissional), e ensaios de pHmetria, com solução alcóolica de fenolftaleína, para detectar regiões com potencial ocorrência de infiltração da água advinda da fachada. 


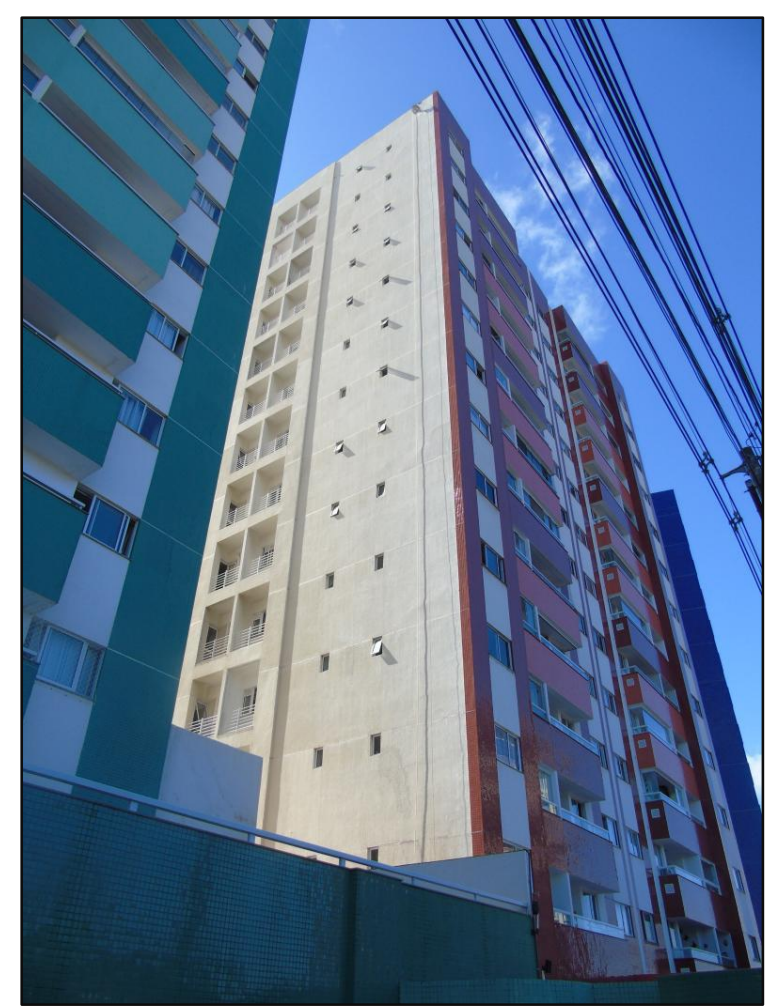

Figura 1 - Vista geral da fachada sudeste

Após deteç̧ão das anomalias, foi feito o diagnóstico do problema e identificadas as prováveis causas das manifestações encontradas, sendo propostas possíveis soluções.

\section{Resultados e discussão}

\subsection{Inspeção Externa}

Durante a inspeção externa foi observada concentração das manifestações patológicas entre o 6ㅇ e 13으 andar. A Figura 2 mostra um desalinhamento da junta de dilatação horizontal no 60 andar, enquanto a Figura 3 mostra falha construtiva similar no 70 andar juntamente com descolamento do selante devido à perda de aderência deste com o substrato. Tal ocorrência foi também encontrada nos outros pavimentos e é o tipo de falha mais comum associada a selantes de fachadas, configurando-se como um problema grave por comprometer a estanqueidade do revestimento.
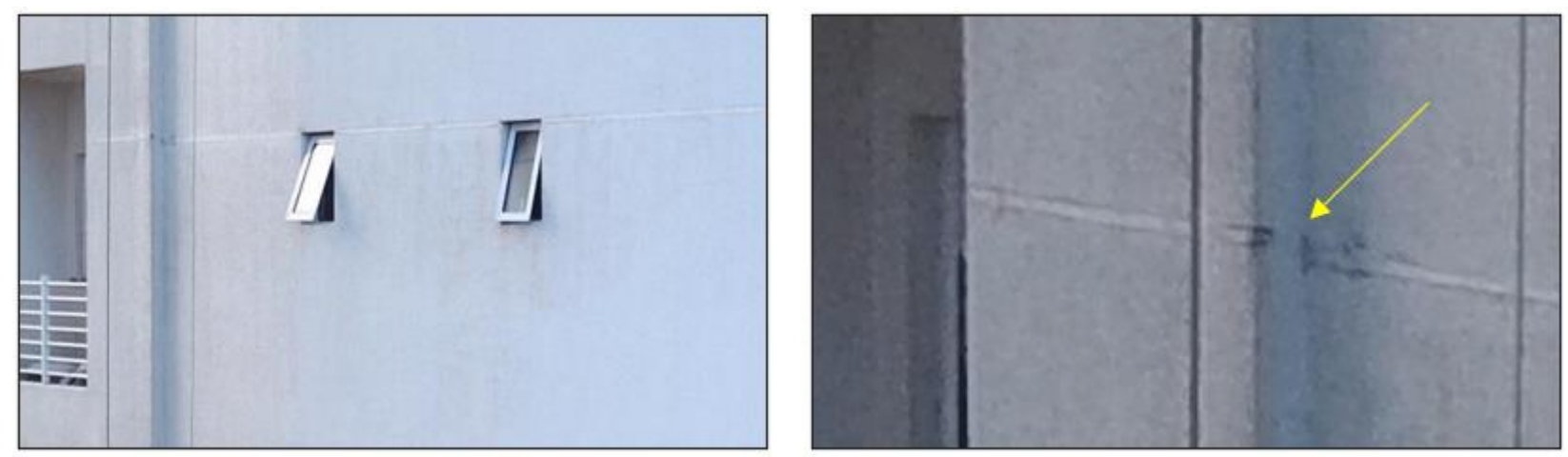

Figura 2 - 60 andar - Desalinhamento da junta (esq.); Detalhe (dir.) 

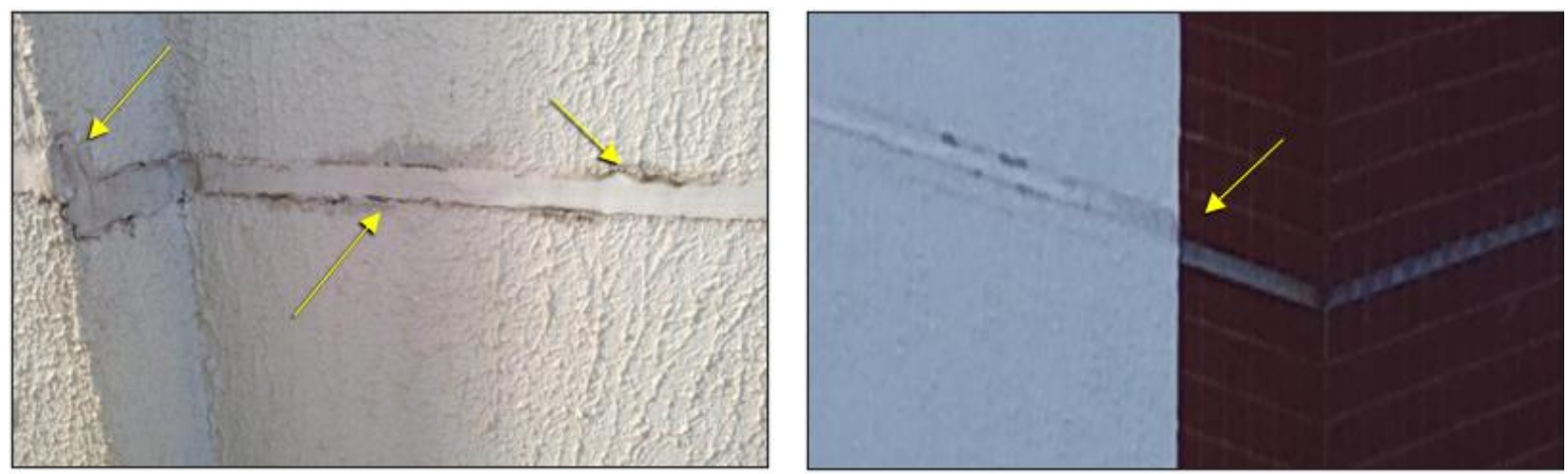

Figura 3 - 7o andar - Descolamento do selante (esq.); Desalinhamento da junta entre revestimentos (dir.)

Foram encontradas fissuras e empolamento do revestimento em textura. O empolamento (Figura 4) tem como possível causa o desgaste precoce da textura por eventos higrotérmicos localizados, enquanto as fissuras (Figura 5) estão associadas à movimentações higrotérmicas do revestimento, originadas por tensões decorrentes de ciclos de molhagem e secagem, sendo visível o acúmulo de umidade na região afetada.
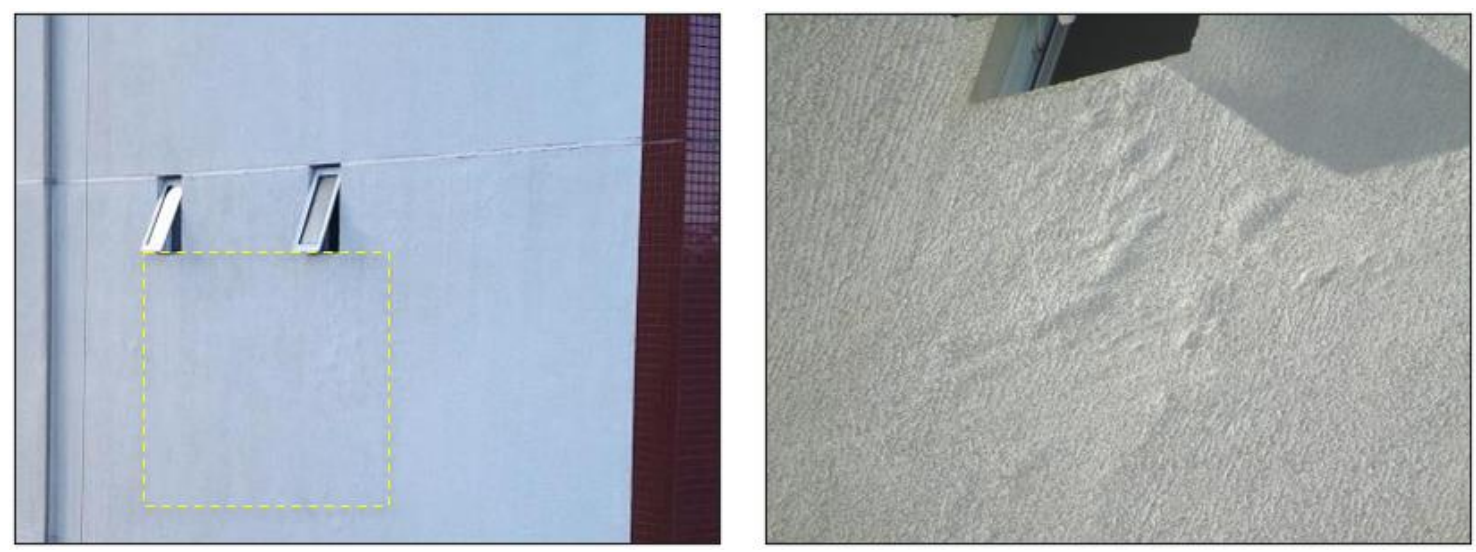

Figura 4 - 10ㅇ andar - Descolamento do selante e região com pintura afetada (esq.); Destaque do empolamento (dir.)
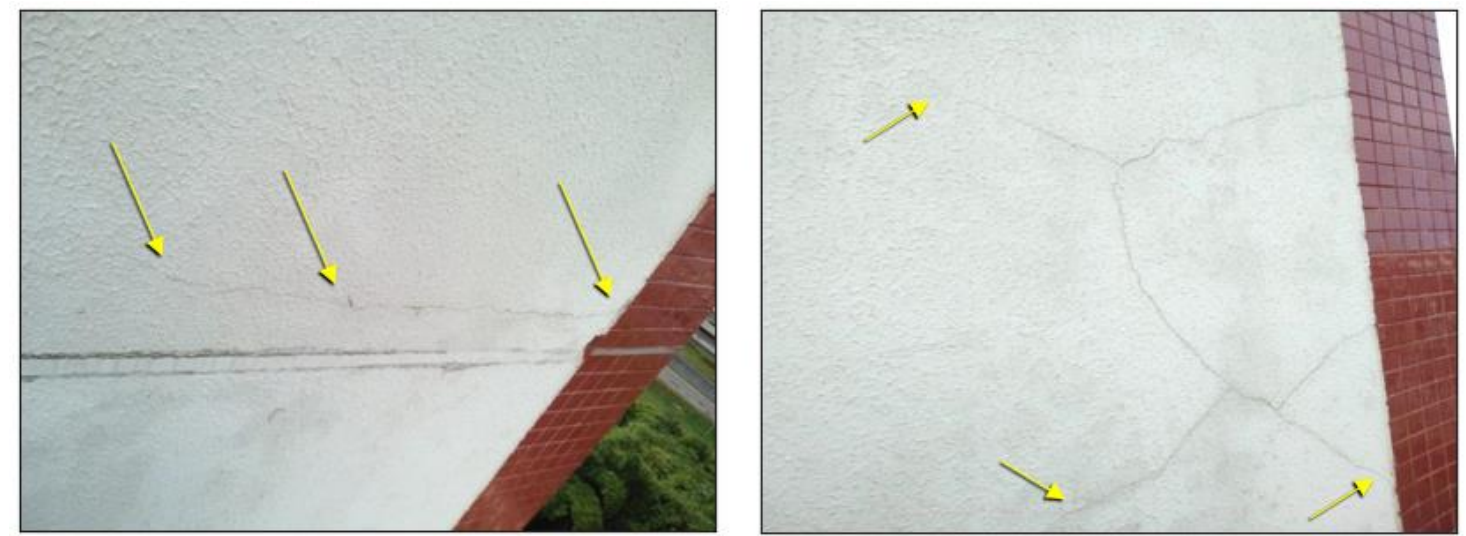

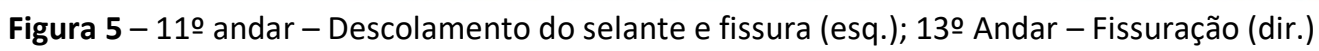

\subsection{Inspeção interna}

\subsection{1 - 7으 Andar}

Após aplicação de água na fachada, foi feita análise termográfica em uma unidade no sétimo andar. Por meio desta foi possível confirmar a presença de umidade, oriunda de infiltrações nas paredes da fachada, destacadas nas regiões com baixa temperatura nos termogramas. Da Figura 6 até a Figura 9 é observada predominância das infiltrações na área próxima ao fundo das vigas, região onde encontram-se as juntas de 
movimentação do revestimento externo. Também foi observado acúmulo de umidade próximo ao piso, em região onde foram detectadas fissuras na fachada.

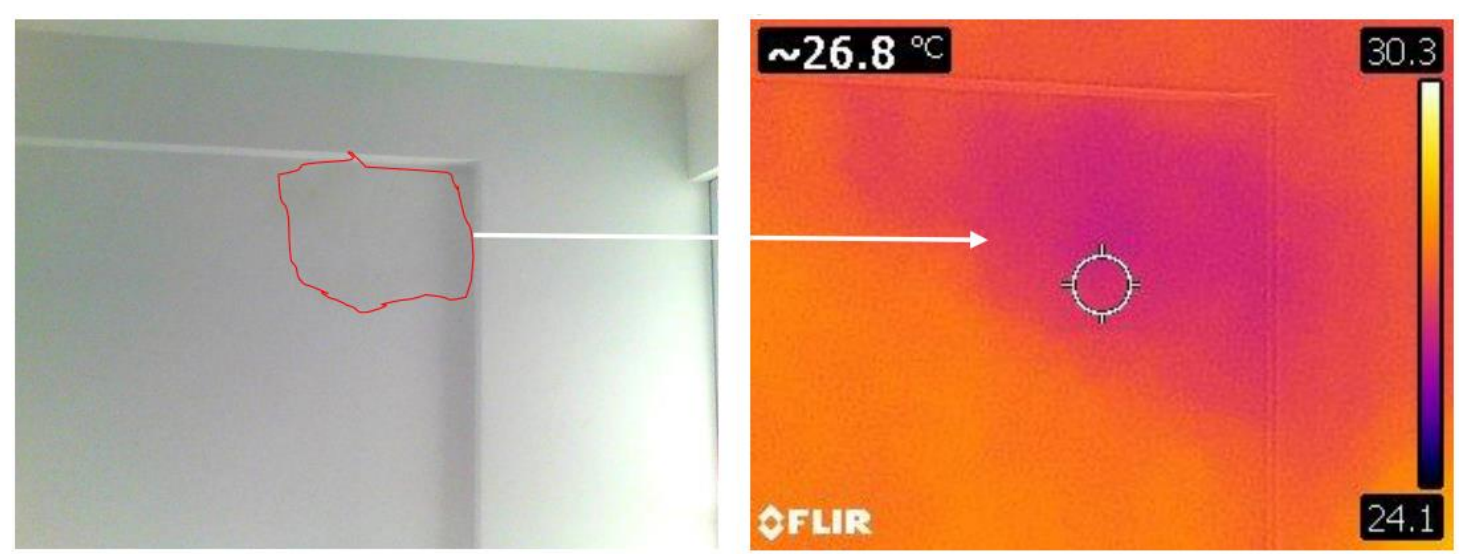

Figura 6 - Termograma do quarto de solteiro, região abaixo da viga
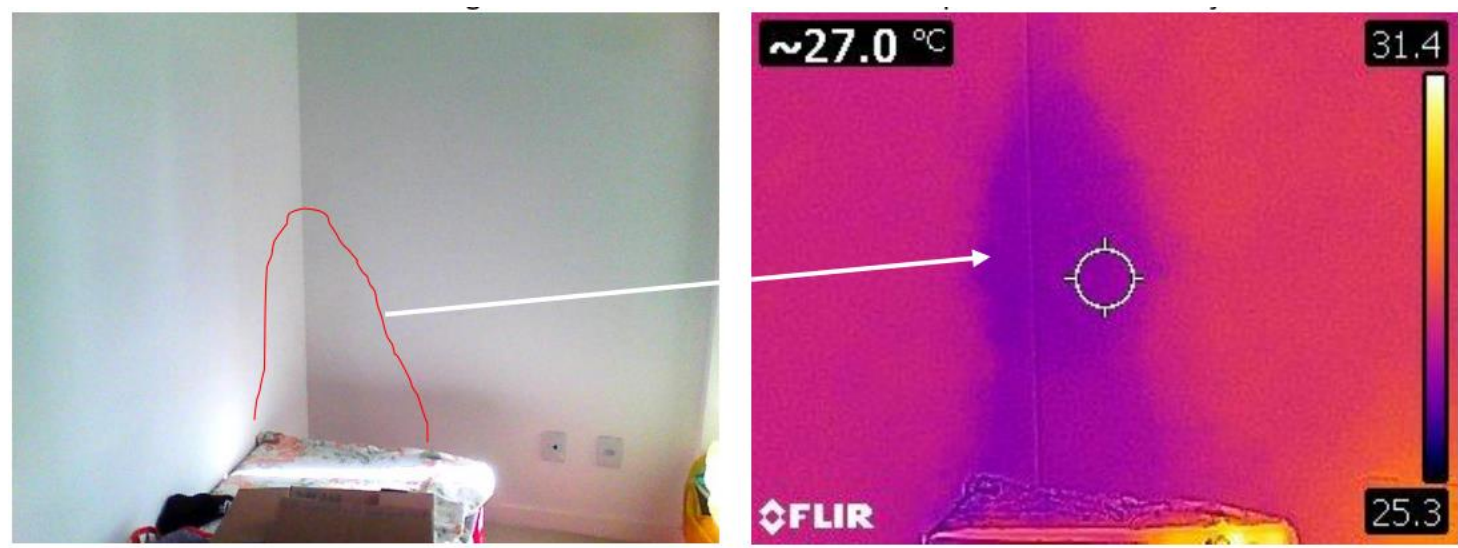

Figura 7 - Termograma do quarto de solteiro, região acima do piso
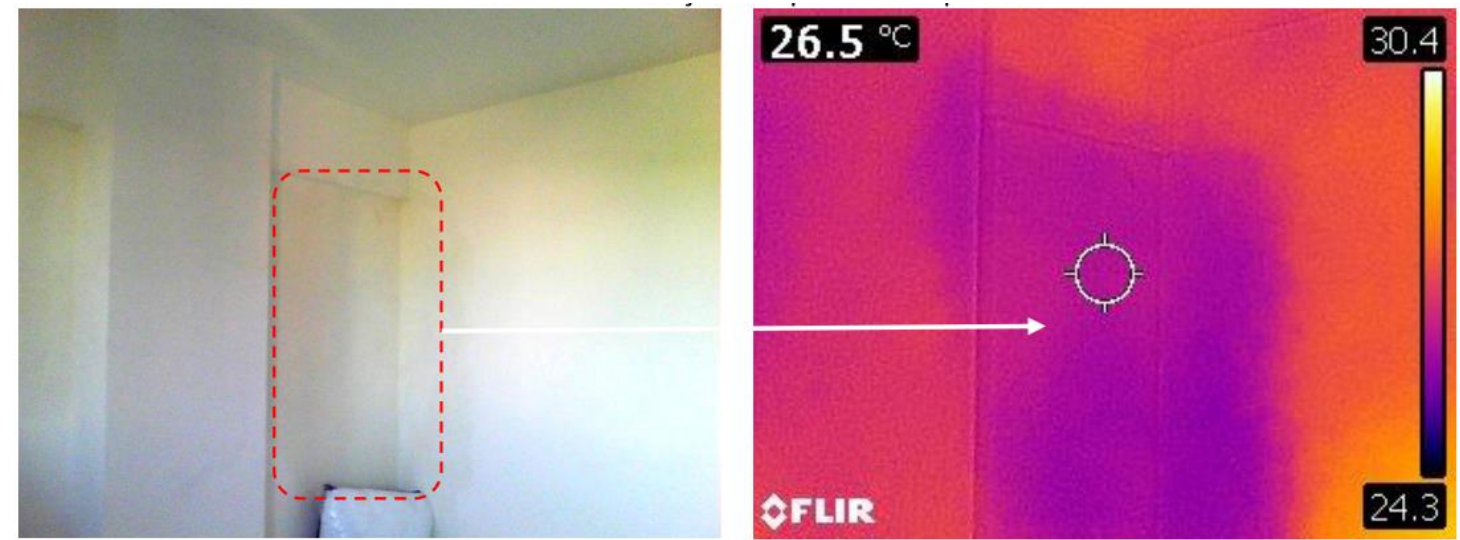

Figura 8 - Termograma do quarto de casal, região de encontro pilar-viga 

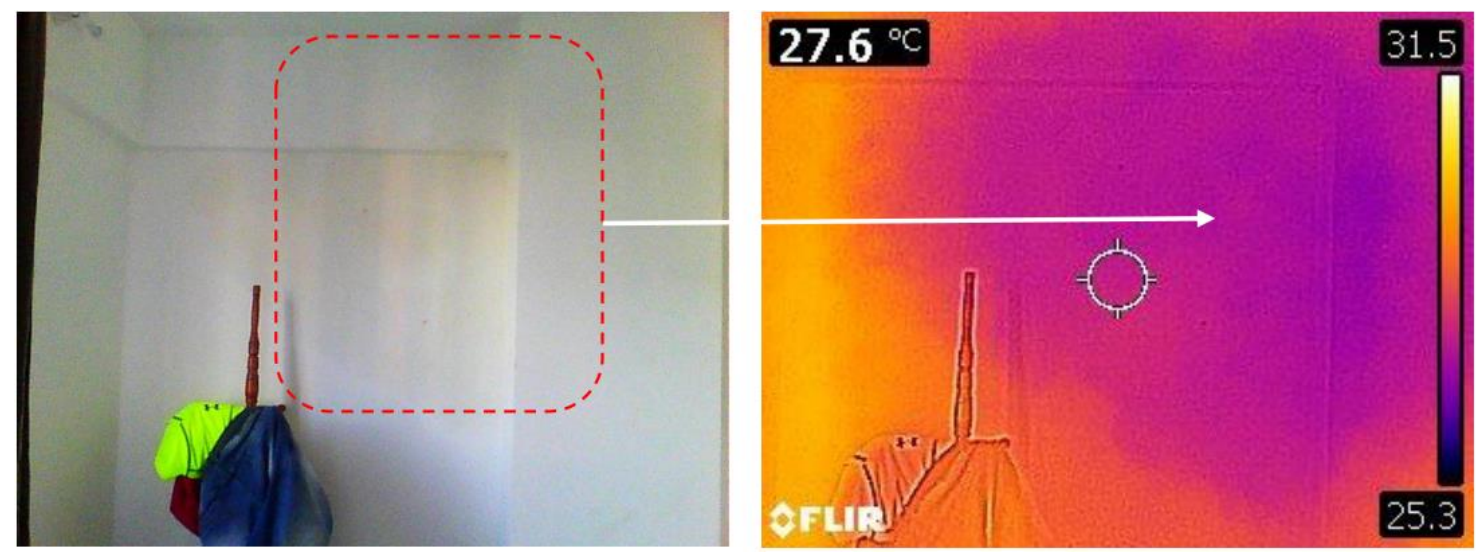

Figura 9 - Termograma do quarto de casal, região abaixo da viga

\subsection{2-11을 Andar}

As mesmas ocorrências foram identificadas na unidade visitada no 11 o andar, sendo apresentado o termograma do quarto de solteiro na Figura 10.

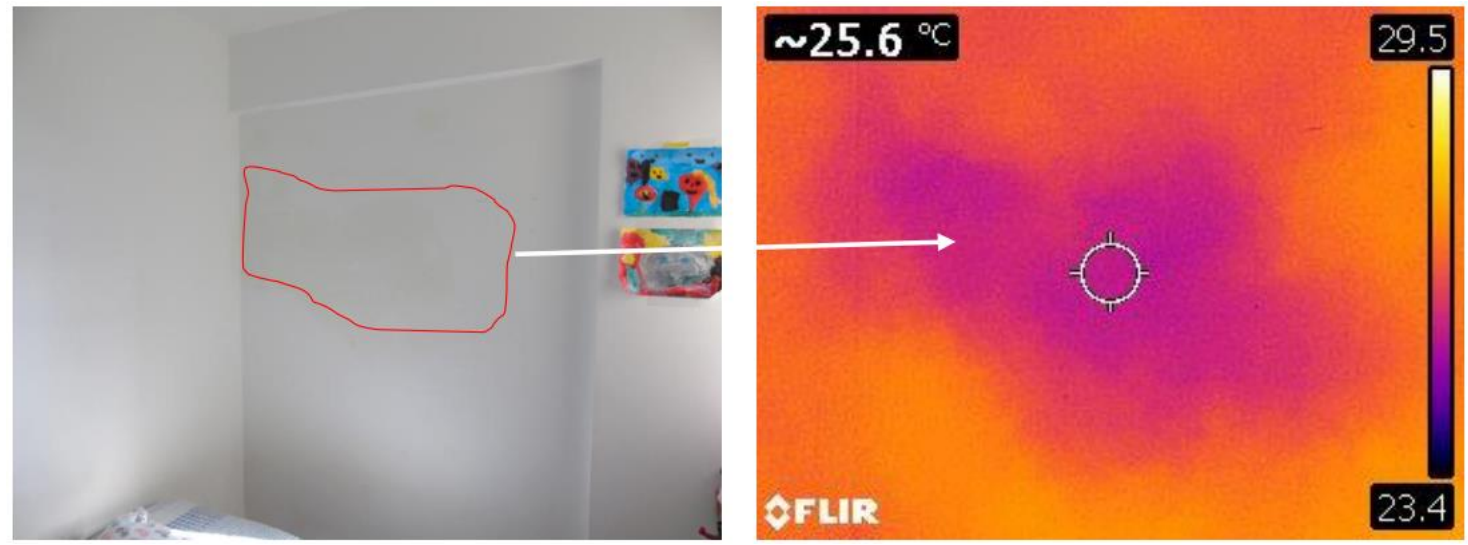

Figura 10 - Termograma do quarto de casal, região abaixo da viga

\subsection{Análises e soluções}

Dado o exposto, constatou-se que a principal causa dos problemas de infiltração identificados foi a falha no selante das juntas de movimentação. Conforme Ribeiro (2006), a perda de aderência dos selantes é uma das principais falhas observadas em juntas seladas, sendo decorrente de fatores como tipo incorreto de selante e falhas de aplicação, sendo importante observar fatores críticos como as condições da superfície (remover completamente as partículas soltas e contaminantes), o uso de primer, o preenchimento adequado da junta (preenchendo a profundidade necessária para criação da área de adesão), temperatura da junta no momento de aplicação e o acabamento final, visando a remoção de bolhas de ar e assegurar o perfil correto do selante.

Também é importante observar que as fissuras por movimentação higrotérmica podem ser potencializadas por características intrínsecas da argamassa de revestimento, tais como elevado teor de ar incorporado, elevada relação água/cimento, excesso de finos, originando fissuras mapeadas.

Dado o exposto, como solução para as infiltrações sugere-se a troca do selante, com remoção total do selante antigo, realizando-se a verificação das juntas quanto à presença de sujidades e partículas soltas e aplicação de novo material com primer, conforme recomendação do fabricante. Além disso, é importante que a intervenção seja executada com a fachada seca, após, no mínimo, 36 horas sem chuva e em condições ensolaradas, sendo observadas as recomendações da NBR 13755 (ABNT, 2017).

Solucionada a principal causa da infiltração no revestimento, procede-se com a recuperação das regiões fissuradas, procedendo-se com a limpeza da região afetada e remoção de partes soltas da pintura. Em seguida, abrem-se, ao longo das fissuras, sulcos com perfil em " $V$ " com ferramenta destinada a tal fim, 
conhecida comercialmente como "abre trincas" (Figura 11). Após abertura dos sulcos, aplica-se um fundo preparador de paredes seguido de duas demãos de selante acrílico, respeitando-se o intervalo de cura e secagem determinado pelos fabricantes.

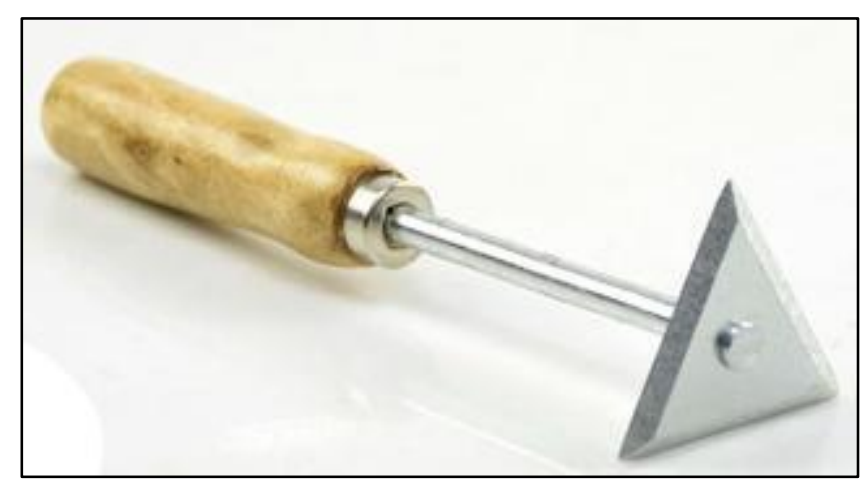

Figura 11 - Ferramenta "Abre trinca"

Como tratamento para o empolamento da textura recomenda-se a reaplicação da textura nas áreas afetadas, isolando-se a região com fita crepe para evitar danos à textura antiga. Após remoção, preparo e aplicação da nova textura, deve-se aguardar o período de cura do fabricante para prosseguir com a pintura da fachada.

\section{Conclusões}

Por meio do exposto foi possível confirmar a relevância da termografia infravermelha para o diagnóstico de infiltrações e problemas associados à presença de umidade. Tal ferramenta se mostra ainda mais valiosa em casos semelhantes ao explorado, onde a infiltração originária da fachada pode ter ocorrência esporádica a depender do regime de chuvas, de modo que algumas regiões afetadas no ambiente interno podem passar desapercebidas em simples avaliações visuais, especialmente em edificações recém-construídas onde a pintura é recente e outros indicadores de infiltração, como manchamentos e formação de fungos, ainda não se desenvolveram. A partir disto, a combinação com as demais técnicas empregadas possibilitou a identificação da causa da patologia e designação de procedimentos adequados para reestabelecimento do desempenho do sistema, reforçando a importância do projeto e execução de procedimentos de manutenção para garantia da habitabilidade e desempenho das edificações.

\section{Agradecimentos}

Agradecemos à Fundação de Amparo à Pesquisa do Estado da Bahia (FAPESB) pelo apoio financeiro e incentivo à pesquisa.

\section{Referências Bibliográficas}

ABNT - Associação Brasileira de Normas Técnicas. (2013). NBR 15575-1: Edificações habitacionais Desempenho Parte 1: Requisitos gerais, Rio de Janeiro.

ABNT - Associação Brasileira de Normas Técnicas. (2014). NBR 6118: Projeto de estruturas de concreto Procedimento, Rio de Janeiro.

Andrade, R. P.; Resende, M. (2019). Estudo da arte da utilização da técnica de termografia embarcada em drones para inspeção de revestimentos de fachadas. TECSIC 2019 - Workshop de Tecnologia de Processos e Sistemas Construtivos. São Paulo.

Antunes, G. R. (2010) Estudo de manifestações patológicas em revestimento de fachada em Brasília sistematização da incidência de casos. Dissertação de Mestrado. Universidade de Brasília, Brasília.

Barreira, E.; Almeida, R. M. S. F.; Delgado, J. M. P. Q. (2016). Infrared thermography for assessing moisture related phenomena in building components. Construction and building materials, v. 110, p. 251-269. 
Cechinel, B. M., Vieira, F. L., Mantelli, P., Tonel, S. (2009). Infiltração em alvenaria-Estudo de caso em edifício na Grande Florianópolis. Caderno de Publicações Acadêmicas, Instituto Federal de Santa Catarina, v. 1, n. 1, p. 16.

Dal Molin, D. C. C., Masuero, A. B., Andrade, J. J. O, Possan, E., Masuero, J. R., Mennucci, M. M. (2016). Contribuição à Previsão da Vida Útil de Estruturas de Concreto. Avaliação de Desempenho de Tecnologias Construtivas Inovadoras: Materiais e Sustentabilidade. p. 223-270. Editora Scienza.

Lisboa, D. W. B., Da Silva, A. B. S., De Souza, A. B. A., Da Silva, M. P. (2018). Utilização de VANT na inspeção de manifestações patológicas em fachadas de edificações. Congresso Técnico Científico da Engenharia e da Agronomia, Maceió.

Ribeiro, F. A.; Barros, M. M. S. B. (2010). Juntas de Movimentação em Revestimentos Cerâmicos de Fachada. São Paulo: Pini.

Santos, C. F.; Rocha, J. H. A.; Povoas, Y. V. (2019). Utilização da termografia infravermelha para detecção de focos de umidade em paredes internas de edificações. Ambiente construído. Porto Alegre, v. 19, n. 1, p. 105-127, Mar.

Schuler, A. (1998). Caracterização de argamassas com adições de sílica ativa como material para reparos e reforços de estruturas de concreto armado. Dissertação (Mestrado). Curso de Pós-graduação em Engenharia Civil, Universidade Federal do Rio Grande do Sul, Porto Alegre.

Tondelo, P. G., Barth, F. (2019). Análise das manifestações patológicas em fachadas por meio de inspeção com VANT. PARC - Pesquisa em Arquitetura e Construção, v. 10. 